\title{
Febrile neutropenia in French emergency departments: results of a prospective multicentre survey
}

Stéphanie André ${ }^{1,2}$, Pierre Taboulet ${ }^{3}$, Caroline Elie ${ }^{2,4}$, Noël Milpied ${ }^{5}$, Michel Nahon ${ }^{2,6}$, Gérald Kierzek ${ }^{2,7}$, Mariève Billemont ${ }^{1}$, Franck Perruche ${ }^{1}$, Sandrine Charpentier ${ }^{8}$, Hélène Clément ${ }^{1}$, Jean-Louis Pourriat ${ }^{1,2,7}$, Yann-Erick Claessens ${ }^{1,2,7^{*}}$

\begin{abstract}
Introduction: Febrile neutropenia (FN) is common in cancer patients receiving myelotoxic therapy. The procedures to treat FN are well established in oncology, but it is unclear whether management is adequate in the emergency department (ED).

Methods: This prospective, multicentre, observational study was carried out in 47 French EDs for 6 months. Patients were adults presenting at the ED with FN after myelotoxic treatment for cancer. Severity of infection was defined according to Bone criteria for severe sepsis and septic shock (SS/SSh) and risk was determined according to Multinational Association of Supportive Care in Cancer (MASCC) criteria. The end point was the implementation of guidelines. Management of patients with SS/SSh required: (i) adequate intravenous (IV) antimicrobial therapy for the first $90 \mathrm{~min}$ (broad-spectrum beta-lactam with or without an aminoglycoside); (ii) fluid challenge $(500 \mathrm{~mL})$; (iii) lactate measurement; (iv) at least one blood culture; and (v) hospitalization. Management of patients without SS/SSh required: (1) no initiation of granulocyte - cell stimulating factor (G-CSF); (2) adequate IV antimicrobial therapy (broadspectrum beta-lactam) and hospitalization if the patient was high-risk according to MASCC criteria; (3) adequate oral antimicrobial therapy (quinolone or amoxicillin/clavulanate or cephalosporin) and hospital discharge if the patient was low-risk.
\end{abstract}

Results: 198 patients were enrolled; 89 patients had SS/SSh, of whom 19 received adequate antimicrobial therapy within 90 min and 42 received appropriate fluid challenge. Blood cultures were obtained from 87 and lactate concentration was measured in 29. Overall, only 6 (7\%) patients with SS/SSh received adequate management. Among 108 patients without SS/SSh, 38 (35\%) were high-risk and 70 (65\%) low-risk. In the high-risk group, adequate antimicrobial therapy was given to 31 patients, G-CSF was initiated in 4 and 35 were hospitalized. In the low-risk group, 4 patients received adequate oral antimicrobial therapy, IV antimicrobial therapy was prescribed in 59, G-CSF was initiated in 12 and six patients were discharged. Adequate management was given to 26/38 (68\%) high-risk and 1/70 low-risk patients. Factors associated with adequate management were absence of SS/SSh $(P=0.0009)$ and high-risk according to MASCC criteria $(P<0.0001)$.

Conclusions: In this French sample of cancer patients presenting to the ED with FN, management was often inadequate and severity was under-evaluated in the critically ill.

\footnotetext{
* Correspondence: yann-erick.claessens@cch.aphp.fr

${ }^{1}$ Department of Emergency Medicine, Hôpital Cochin, APHP, 27, rue du

Faubourg Saint-Jacques, F-75679 Paris Cedex 14, France
} 


\section{Introduction}

The occurrence of febrile neutropenia in cancer patients should lead to cautious severity assessment in order to provide appropriate management and therefore improve prognosis [1]. Despite specific recommendations, febrile neutropenia is still associated with high morbidity and mortality [2] and elevated health-related costs. The underlying conditions associated with febrile neutropenia make patients more vulnerable. Cancer itself compromises survival [3], impairs innate and adaptative immunity, and patients have a higher chance of developing a nosocomial infection [4]. Therefore, severe infections are common in this population. To help physicians safely decide the site of care for patients with febrile neutropenia, criteria have been determined [5], and sensitive scoring systems have been validated to limit patients' misclassification [6]. In this setting, Multinational Association for Supportive Care in Cancer (MASCC) criteria were developed to help physicians make decisions about the site of care and overall management of patients with febrile neutropenia. This score mainly relies on subjective criteria such as the evaluation of clinical symptoms and hydration state.

Sepsis, severe sepsis and septic shock were defined 15 years ago as a continuum of increasing severity of the host response to the pathogen [3] closely related to predisposition, organ failure and systemic response, and to the microorganism and site of infection [7]. Management of septic patients has significantly improved over the past decade as a result of consensus guidelines published by 11 scientific societies [8-10]. These recommendations have been widely disseminated, but detecting patients at risk remains a daily challenge in emergency medicine.

The presence of cancer may impair the prognosis of acute patients [8], including septic patients [11] visiting the emergency department (ED) [12]. Reports on the management of febrile neutropenia in EDs are scarce, retrospective and mainly single centre studies. Interestingly, a French survey based on declarative questionnaires reported that 1 out of 31 cancer teams involved emergency physicians in their organizational strategy to manage patients with febrile neutropenia [13]. As the incidence of sepsis has increased in the general population [14], more patients visit the ED for this reason [15] and this had led to a dramatic increase in number of cancer patients in this setting [16].

This study was carried out to describe the management of patients with febrile neutropenia in EDs and to determine how management complies with recommendations. The secondary objective was to determine the factors associated with adequate management.

\section{Materials and methods}

\section{Study design and ethics}

This was a prospective multicentre study carried out in 47 French EDs over a six-month period (4 February to 4 August, 2008). The inform consent from patients was required for this study. The study protocol and patient information procedures were approved by the institutional review board for the protection of human subjects of the Cochin Port-Royal (Paris, France).

\section{Recruitment of patients}

Patients were included if they were adults ( $>18$ years old) who presented at a participating ED with febrile neutropenia after myelotoxic treatment for cancer. Delay between last cytotoxic treatment and occurrence of febrile neutropenia was not pre-specified to enter the study. Definition of febrile neutropenia consisted of a white blood cell count less than $1,000 / \mu \mathrm{L}$ (or neutrophils $<500 / \mu \mathrm{L}$ ), with a core temperature above $8.3^{\circ} \mathrm{C}$ (or $>38^{\circ} \mathrm{C}$ on two consecutive occasions). Patients who presented with febrile neutropenia in another setting or who refused to participate were not included in the study.

\section{Procedure and data collection}

An investigator (SA) contacted by phone the team leader of each participating centre to describe the study and explain criteria for eligibility. Each team leader gave the information about this study to the ED team. The physician on duty invited eligible patients to participate and implemented the electronic form. As this was an observation study, data were collected on the basis of usual practices.

The characteristics of each participating centre were recorded, with special reference to the management of febrile neutropenia. Data collected for each patient included demographic characteristics, physical data and medical history focusing on cancer and outcome (discharge, admission, admission to an ICU, death).

\section{Study objectives}

The primary objective was to describe the management of patients with febrile neutropenia in EDs and to determine whether management complies with recommendations. The secondary objective was to determine the factors associated with adequate management.

Evaluation criteria in the guidelines were identified to accurately assess the primary end points. Patients with febrile neutropenia were divided into two groups: those with and those without severe sepsis or septic shock (SS/SSh).

Patients with SS/SSh were selected according to the following criteria $[9,17]$ : blood lactate more than $4 \mathrm{mmol} / \mathrm{L}$, or low blood pressure before fluid challenge 
(systolic blood pressure $<90 \mathrm{mmHg}$ or $40 \mathrm{mmHg}$ below usual systolic blood pressure), or at least one organ dysfunction (pulse oxymetry $\left[\mathrm{SpO}_{2}\right]<95 \%$ with fraction of inspired oxygen $>0.5$, blood creatinine $>176 \mu \mathrm{mol} / \mathrm{L}$ or oliguria, international normalised ratio $>2$, bilirubinemia $>78 \mu \mathrm{mol} / \mathrm{L}$, Glasgow Coma Scale <15). Thrombopenia was excluded from the criteria because of the potential effect of chemotherapy on platelet counts. Patients without SS/SSh were identified as high risk or low risk according to the MASCC classification [6] (Table 1). Of note, data that allowed determination of MASCC and presence of SS/SSh were collected at the bedside by attending physicians. Implementation of the database was not intended to help physicians detecting the severity of a patient's condition.

Implementation of the following guidelines was assessed. Management of patients with SS/SSh required for the 90 first minutes $[9,10]$ : (i) a dose regimen of adequate (broad-spectrum) intravenous antimicrobial therapy; (ii) fluid challenge $(500 \mathrm{~mL})$ if mean arterial blood pressure was less than $65 \mathrm{mmHg}$; (iii) lactate measurement; (iv) at least one blood culture; and (v) hospitalization. Management of patients without SS/SSh who were high risk according to MASCC criteria required [18-20]: (i) adequate intravenous antimicrobial agent (broad-spectrum beta-lactam with or without an aminoglycoside); (ii) no initiation of granulocyte-cell stimulating factor (G-CSF); and (iii) hospitalization. Management of patients without SS/SSh who were low-risk according to MASCC criteria required [18-20]: (i) adequate oral antimicrobial agent (quinolone or amoxicillin/clavulanate or cephalosporin); (ii) no initiation of G-CSF; and (iii) hospital discharge.

Patients were divided into two groups; those managed according to recommendations and those who were not, irrespective of initial severity. The two populations were compared to determine the factors associated with adequate management.

Table 1 Classification according to the Multinational Association for Supportive Care in Cancer(MASCC) [6]

\begin{tabular}{ll}
\hline Variables & $\begin{array}{c}\text { Points } \\
\text { (Low-risk if score } \mathbf{2 0} \text { ) }\end{array}$ \\
\hline Burden of illness & 2 \\
Age $<60$ years & 3 \\
Outpatient status & 4 \\
No chronic obstructive pulmonary disease & 4 \\
No previous fungal infection & \\
Clinical state at admission & 5 \\
No or mild symptoms & 3 \\
Moderate symptoms & 5 \\
Systolic blood pressure $<90 \mathrm{mmHg}$ & 3 \\
No dehydration needing perfusion &
\end{tabular}

\section{Statistical analysis}

Quantitative variables are described as the mean \pm standard deviation or median (range) and quantitative variables as number and percent. The adequacy of management according to recommendations was determined for the two subgroups using Pearson's chi-squared test or Fisher's exact test for qualitative variables and the Student's t test or Wilcoxon rank sum test for quantitative variables. All tests were two-sided. A $P$ value of less than $5 \%$ were considered statistically significant. All statistical analyses were carried out using R software (Vienna University of Economics and Business, 1090 Vienna, Austria).

\section{Results}

\section{Emergency departments}

The 47 participating EDs were distributed across France and were representative of each metropolitan region. Thirteen $(28 \%)$ centres were tertiary teaching hospitals, six $(13 \%)$ were in the Paris area and $29(60 \%)$ had a dedicated unit for cancer patients. The median number of hospital beds was 500 (range, 150 to 2900) and the median number of ED visits was 17,679 during the six months of the study (range, 3,000-39,045). A written procedure for the management of febrile neutropenia was present in 19 EDs (40\%) and was formalised with oncologists/haematologists in 15 (32\%). This procedure referred to protective isolation in $10(21 \%)$, antimicrobial agents in 16 (34\%) and growth factors in 5 (11\%) EDs.

\section{Study participants and febrile neutropenia}

Among the 777,876 patients who visited the EDs during the study period, 198 fulfilled the inclusion criteria (mean age $61 \pm 14$ years, $116(60 \%)$ male) corresponding to one case every 3,930 visits; all these patients accepted to participate (Figure 1). Thirteen centres included five patients or more (Tables 2 and 3).

A solid neoplasm was reported in 111 patients (56\%) and haematological cancer in 87 (44\%). Seventy-four patients $(39 \%)$ had an underlying disorder. Patients often self-referred to the ED ( $\mathrm{n}=87,44 \%)$. Forty-seven (24\%) patients were treated with G-CSF to prevent neutropenia and 174 (88\%) had one or more risk factors that should have prompted the prophylactic use of G-CSF (Table 4).

The characteristics of the patients are summarised in Table 5. Median delay between chemotherapy and ED visit was 10 days, ranging from 4 to 35 days. According to the criteria selected for disease severity, 89 (45\%) patients had SS/SSh, 108 (55\%) did not have SS/SSh and one could not be classified.

Among the 89 patients with SS/SSh, ED physicians recognised the severity signs in 45 (55\%). Blood cultures were obtained from 87 (98\%) patients and lactate concentration was measured in 29 (32\%). Antimicrobial 


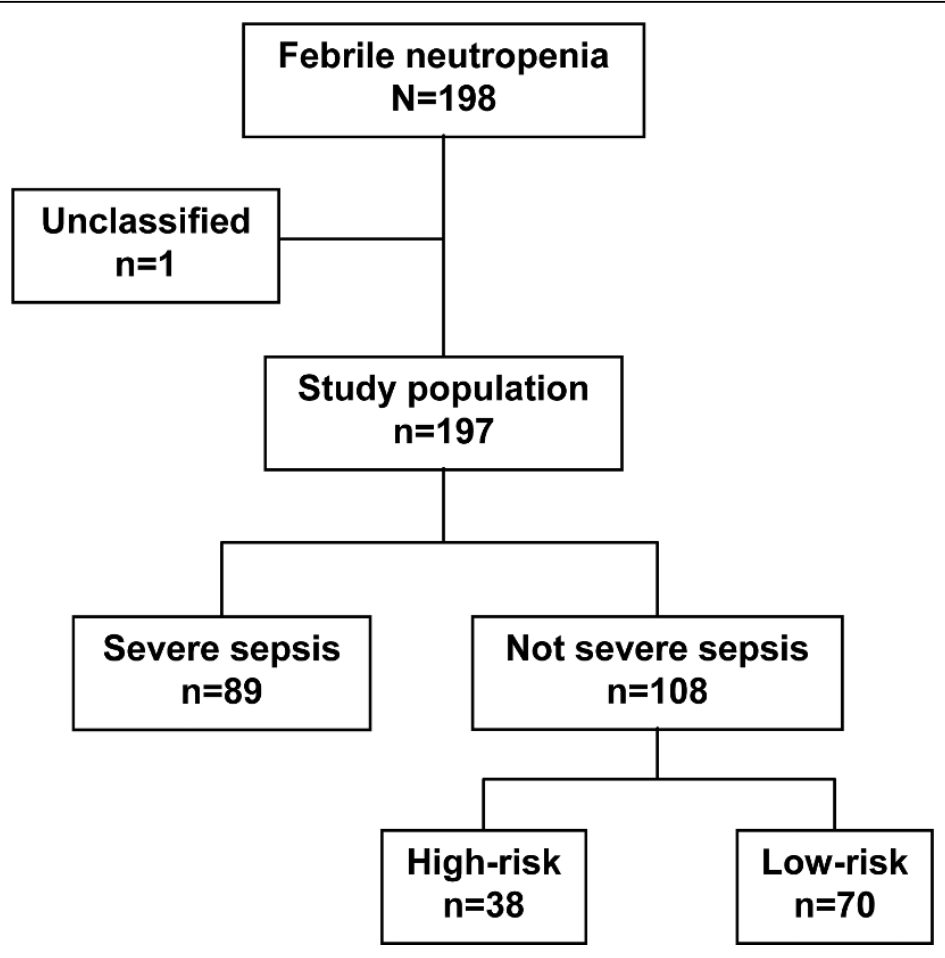

Figure 1 Flow chart of patients included in the study

Table 2 Characteristics of participating centres

\begin{tabular}{lc}
\hline Variables & $\begin{array}{c}\text { Number (\%) } \\
\text { Mean (range) }\end{array}$ \\
\hline Participating centres: & 47 \\
$\quad$ Tertiary teaching hospitals & $13(27 \%)$ \\
$\quad$ General community hospitals & $35(74 \%)$ \\
Number of beds in hospital & $500(150-2,900)$ \\
Number of ED visits during the study period & $17,679(3,000-$ \\
& $39,045)$ \\
Number of included patients: & 198 \\
$\quad$ Tertiary teaching hospitals & $111(56 \%)$ \\
General community hospitals & $87(44 \%)$ \\
Number of centres with $\geq 5$ patients & $13(27 \%)$ \\
Written procedure for the management of febrile & $19(40 \%)$ \\
neutropenia & \\
Formalised with oncologists/haematologists & $15(79 \%)$ \\
$\quad$ Protective isolation & $10(53 \%)$ \\
Antimicrobial agents & $16(84 \%)$ \\
$\quad$ Prescription of G-CSF
\end{tabular}

ED, emergency department; G-CSF, granulocyte-cell stimulating factor.

therapy with a broad-spectrum beta-lactam was started within 90 minutes in 19 of 86 (22\%) patients (data missing for three). Among these patients, nine (10\%) also received an aminoglycoside. Appropriate fluid challenge was given to $43(49 \%)$ patients and 88 were hospitalised (99\%), including 18 who were admitted to the ICU. Only six (7\%) patients with SS/SSh received adequate management (Table 6). Of note, G-CSF was initiated in the ED in 12 patients (14\%) with SS/SSh.

There were 108 patients without SS/SSh: 38 were high risk (35\%) and 70 were low risk (65\%) according to MASCC criteria. In the high-risk category, adequate antimicrobial therapy was given to 31 (81\%) patients, G-CSF was initiated in the ED in four (10\%) and 35 (95\%) were hospitalised. In the low-risk category, four (6\%) patients received an adequate oral antimicrobial agent, but an IV antimicrobial agent was prescribed in $59(84 \%)$ cases. G-CSF was initiated in the ED in $12(17 \%)$ patients. Only six patients $(9 \%)$ were discharged; the remaining patients were believed to have been admitted. Adequate management was proposed in 27 of 108 (25\%) patients without SS/SSh, 26 (68\%) highrisk patients and one low-risk patient (Table 2).

The 33 (17\%) patients who were given adequate management were compared with the 161 (83\%) patients managed inadequately (important data were missing in four patients that were excluded from the analysis). Patients without SS/SSh were significantly more likely to receive adequate management than those with $\mathrm{SS} / \mathrm{SSh}$ $(P=0.00009)$. On the other hand, adequate management was proposed in 32 of 103 high-risk patients (31\%) whereas only 1 low-risk patient out of $91(P<0.0001)$ was treated according to recommendations (Table 7 ). 
Table 3 Details of location, activity, inclusions and dedicated unit for cancer patients in participating centres

\begin{tabular}{|c|c|c|c|c|}
\hline Hospital centres & $\begin{array}{l}\text { Number of } \\
\text { inclusions }\end{array}$ & $\begin{array}{l}\text { Number of ED visits } \\
\text { during study period }\end{array}$ & $\begin{array}{l}\text { Presence of } \\
\text { cancer unit }\end{array}$ & $\begin{array}{c}\text { Management procedure for } \\
\text { febrile neutropenia }\end{array}$ \\
\hline (01) Ain: CH Bourg-en-Bresse & 2 & 15,500 & Yes & Yes \\
\hline (03) Allier: CH Vichy & 1 & 15,700 & No & No \\
\hline (06) Alpes Maritimes: CHU Nice & 2 & 34,300 & Yes & No \\
\hline (07) Ardèche: CH Annonay & 2 & 11,000 & No & Yes \\
\hline (07) Ardèche: $\mathrm{CH}$ Aubenas & 1 & ND & Yes & No \\
\hline (09) Ariège: CH Val d'Ariège & 1 & 13,200 & No & No \\
\hline (13) Bouches-du-Rhône: CH Martigues & 3 & 16,991 & No & No \\
\hline (15) Cantal: CH Aurillac & 2 & 12,444 & Yes & No \\
\hline (15) Cantal: CH Mauriac & 1 & 3,000 & No & No \\
\hline (17) Charente-Maritime: CH La Rochelle & 3 & 21,500 & No & No \\
\hline (17) Charente-Maritime: CH Rochefort sur mer & 3 & 10,500 & ND & ND \\
\hline (19) Corrèze: CH Tulles & 1 & 9,000 & No & No \\
\hline (22) Côtes d'Armor: CH St Brieuc & 2 & 22,500 & Yes & Yes \\
\hline (24) Dordogne: CH Périgueux & 2 & 14,900 & No & Yes \\
\hline (26) Drôme: CH Valence & 5 & 19,130 & Yes & Yes \\
\hline (28) Eure-et-Loire: CH Chartres & 2 & 19,336 & Yes & No \\
\hline (35) Ile-et-Vilaine: CH St Malo & 1 & 18,000 & Yes & Yes \\
\hline (36) Indre: CH Le Blanc & 1 & 4,570 & ND & ND \\
\hline (37) Indre-et-Loire: CH Chinon & 3 & 6,857 & Yes & Yes \\
\hline (37) Indre-et-Loire: CHU Tours & 8 & 24,000 & Yes & Yes \\
\hline (38) Isère: CHU Grenoble & 5 & 35,600 & Yes & Yes \\
\hline (40) Landes: CH Mont-de-Marsan & 5 & ND & Yes & No \\
\hline (42) Loire: CHU St Etienne & 13 & 20,232 & Yes & No \\
\hline (44) Loire Atlantique: CH Chateaubriant & 1 & 7,000 & No & No \\
\hline (45) Loiret: CH Montargis & 4 & 15,222 & Yes & Yes \\
\hline (45) Loiret: CH Orléans & 6 & 19,500 & Yes & No \\
\hline (47) Lot-et-Garonne: CH Agen & 1 & 10,000 & No & No \\
\hline (49) Maine-et-Loire: CHU Angers & 4 & 23,882 & Yes & Yes \\
\hline (54) Meurthe-et-Moselle: CH Lunéville & 1 & 8,200 & No & No \\
\hline (59) Nord: CH Dunkerque & 6 & 26,156 & Yes & Yes \\
\hline (62) Pas de Calais: CH St Omer & 1 & ND & ND & ND \\
\hline (63) Puy de Dôme: CH Thiers & 1 & 6,000 & No & No \\
\hline (63) Puy de Dôme: CHU Clermont Ferrand & 4 & 22,000 & Yes & No \\
\hline (64) Pyrénnées Atlantiques: CH Bayonne & 2 & 15,000 & Yes & Yes \\
\hline (64) Pyrénnées Atlantiques: CH Pau & 2 & 13,000 & Yes & No \\
\hline (71) Saône-et-Loire: CH Mâcon & 1 & 17,025 & Yes & ND \\
\hline (72) Sarthre: CH Le Mans & 1 & 28,643 & Yes & Yes \\
\hline (75) Paris: CHU Cochin & 22 & 23,368 & Yes & Yes \\
\hline (75) Paris: CHU Hôtel Dieu & 3 & 22,586 & Yes & Yes \\
\hline (75) Paris: CHU Pitié & 9 & 39,045 & Yes & No \\
\hline (75) Paris: CHU Saint Antoine & 1 & 23,710 & Yes & Yes \\
\hline (75) Paris: CHU Saint Louis & 38 & 16,948 & Yes & Yes \\
\hline (75) Paris: CHU Tenon & 5 & 22,261 & No & No \\
\hline (79) Deux Sèvres: CH Niort & 1 & 17,700 & Yes & No \\
\hline (81) Tarn: CH Albi & 3 & 14,587 & No & No \\
\hline (91) Essonne: CH Longjumeau & 6 & 15,000 & Yes & Yes \\
\hline (94) Créteil: CHU Henri Mondor & 5 & 22,783 & Yes & No \\
\hline
\end{tabular}

ED, emergency department, ND, not determined. 


\section{Table 4 Prescription of G-CSF}

\begin{tabular}{lc}
\hline Variables & Number (\%) \\
\hline Prophylactic prescription of G-CSF before referral in ED & $47(24)$ \\
Age $>65$ years & $14(30)$ \\
Recurrent or resistant cancer & $28(60)$ \\
Chemotherapy at high-risk for neutropenia (risk >20\%) & $15(38)$ \\
Previous history of febrile neutropenia & $15(32)$ \\
Prescription of G-CSF initiated in ED & $27(19)$ \\
Patients with severe sepsis & $12(44)$ \\
\hline
\end{tabular}

ED, emergency department; G-CSF, granulocyte-cell stimulating factor.

\section{Discussion}

The results of this study suggest that cancer patients with febrile neutropenia visiting the ED are likely to present with SS/SSh, and their management does not comply with current guidelines especially in those with more severe infections.

The 47 participating centres were distributed across France and presented heterogeneous characteristics. This was representative of French EDs overall. As only 60\% of hospitals had a dedicated cancer unit, it was assumed that cancer patients with febrile neutropenia visited community hospitals with this acute adverse event. This suggests that procedures to treat these patients should be available in every ED. However, only $40 \%$ of participating centres reported a written protocol for the management of febrile neutropenia. A total of 198 consecutive patients with febrile neutropenia were included in the study. The demographic characteristics of these patients corresponded to epidemiologic data published by the French Institute Survey for cancer [16].

EDs are first dedicated to the management of patients with severe disorders including severe infections. A recent study reported that SS/SSh accounted for more than 500,000 visits annually in US EDs [21]. In addition, the incidence of severe sepsis is increasing [22], cancer is a predisposing factor for sepsis, and the number of cancer patients will almost double within one decade [23]. Optimising prevention of febrile neutropenia is therefore an important part of the management. Forty-seven $(24 \%)$ patients were treated with

Table 5 Characteristics of the patients

\begin{tabular}{|c|c|c|c|c|}
\hline & Total population & Patients with severe sepsis & Patients without severe sepsis & $P$ \\
\hline Number of patients & 198 & 89 & 108 & \\
\hline Age (years), mean $\pm S D$ & $61 \pm 14$ & $65 \pm 13$ & $57 \pm 14$ & $<0.001$ \\
\hline Female, n (\%) & $79(41)$ & $30(34)$ & $49(46)$ & 0.11 \\
\hline Karnofsky index, median (range) & $70(30-100)$ & $70(30-100)$ & $80(30-100)$ & 0.06 \\
\hline Underlying disorders, n (\%) & $73(38)$ & $36(43)$ & $37(35)$ & 0.32 \\
\hline Chronic pulmonary disease & $9(12)$ & $6(16)$ & $3(3)$ & \\
\hline Chronic heart failure & $12(16)$ & $9(24)$ & $3(3)$ & \\
\hline Cirrhosis & $7(9)$ & $4(11)$ & $3(3)$ & \\
\hline Hemodialysis chronic renal failure & $2(3)$ & $2(5)$ & 0 & \\
\hline Severe neurological disorder & $3(4)$ & $1(3)$ & $2(2)$ & \\
\hline Other & $51(69)$ & $21(57)$ & $30(29)$ & \\
\hline Haematological neoplasm, n (\%) & $87(44)$ & $40(45)$ & $47(44)$ & 0.84 \\
\hline Lymphoproliferation & $64(32)$ & $30(34)$ & $34(31)$ & \\
\hline Myeloproliferation & $22(11)$ & $10(11)$ & $12(11)$ & \\
\hline Undetermined & 1 & 0 & 1 & \\
\hline Solid cancer & $111(56)$ & $49(55)$ & $61(56)$ & \\
\hline Lung & $39(20)$ & $24(27)$ & $15(14)$ & \\
\hline Breast & $26(13)$ & $9(10)$ & $17(16)$ & \\
\hline Urological and genital & $18(9)$ & $9(10)$ & $9(8)$ & \\
\hline Gastro-intestinal & $13(7)$ & $5(6)$ & $7(6)$ & \\
\hline Other or undetermined & $15(8)$ & 1 & $8(7)$ & \\
\hline Presence of metastasis or uncontrolled & $133(67)$ & $69(78)$ & $63(58)$ & 0.004 \\
\hline Previous history of febrile neutropenia & $60(31)$ & $24(27)$ & $36(35)$ & 0.32 \\
\hline Chemotherapy at high-risk for neutropenia & $36(23)$ & $15(21)$ & $21(25)$ & 0.57 \\
\hline Corticosteroids & $83(42)$ & $37(42)$ & $46(43)$ & 0.89 \\
\hline Prophylaxis with G-CSF & $47(25)$ & $18(20)$ & $29(28)$ & 0.22 \\
\hline Antimicrobial therapy prior to ED & $48(25)$ & $15(17)$ & $33(31)$ & 0.03 \\
\hline MASCC $<20$ (high-risk) & $105(53)$ & $67(75)$ & $38(35)$ & $<0.001$ \\
\hline
\end{tabular}

Results are expressed as number (\%), mean \pm standard deviation (SD), or median (range). $P$ values below 0.05 are statistically significant. ED, emergency department; G-CSF, granulocyte-cell stimulating factor; MASCC, Multinational Association for Supportive Care in Cancer 
Table 6 Characteristics of the management of febrile neutropenia in patients with or without severe sepsis

\begin{tabular}{|c|c|c|c|}
\hline \multirow[t]{2}{*}{ Management in the ED } & \multirow{2}{*}{$\begin{array}{l}\text { Patients with severe sepsis } \\
\qquad(\mathrm{n}=89)\end{array}$} & \multicolumn{2}{|c|}{ Patients without severe sepsis } \\
\hline & & $\begin{array}{c}\text { High risk } \\
(\mathrm{n}=38)\end{array}$ & $\begin{array}{l}\text { Low risk } \\
(n=70)\end{array}$ \\
\hline Adequate antimicrobial therapy & $28(32)$ & $30(81)$ & $31(44)$ \\
\hline \multicolumn{4}{|l|}{ Supportive treatment } \\
\hline Fluid challenge & $43(49)$ & $5(14)$ & $6(9)$ \\
\hline Vasoactive drugs & $6(7)$ & $0(0)$ & $0(0)$ \\
\hline \multicolumn{4}{|l|}{ Laboratory data } \\
\hline Lactate concentration & $29(33)$ & $1(3)$ & $11(16)$ \\
\hline Blood cultures & $87(99)$ & $36(100)$ & $63(93)$ \\
\hline New prescription of G-CSF & $12(14)$ & $4(11)$ & $12(17)$ \\
\hline Adequate orientation & $88(99)$ & $35(95)$ & $6(9)$ \\
\hline Global adequate management & $6(7)$ & $26(68)$ & $1(1)$ \\
\hline
\end{tabular}

Risk of patients without severe sepsis was determined using MASCC criteria (low risk if MASCC $\geq 20$; high risk if MASCC $<20$ ). All results are expressed as number (\%). ED, emergency department; G-CSF, granulocyte-cell stimulating factor; MASCC, Multinational Association for Supportive Care in Cancer.

G-CSF to prevent febrile neutropenia, whereas $174(88 \%)$ had one or more risk factors that should have prompted the prophylactic use of G-CSF [24]. In our sample, there was an under-use of G-CSF in patients at risk of febrile neutropenia. The under-use of G-CSF in oncology practice was also reported previously by Hayes [25]. We therefore believe that emergency physicians will have increasing chances to treat febrile neutropenia.

In their series used to derive and validate the Mortality in Emergency Department Sepsis (MEDS) score, Shapiro and colleagues reported that $35.5 \%$ and $2.5 \%$ of patients visiting the ED with infection had severe sepsis and septic shock, respectively [12]. Here we reported that $89(45 \%)$ patients with febrile neutropenia presented with SS/SSh. This underscores that chemotherapy-related neutropenia in cancer patients is a risk factor for developing severe infection. In our series, very few patients that developed severe infections were treated according to current guidelines. Indeed, adequate management was initiated in only six patients. This may suggest that detecting severe infections is challenging for emergency physicians. Initial severity assessment is sometimes falsely reassuring and patients may worsen during their stay in the ED [26]. A study conducted in Brazil [14] reported that ED physicians were able to detect severe infection in $15.8 \%$ of cases. Implementation of the Surviving Sepsis Campaign guidelines improved detection of severe infections but $61.5 \%$ of patients remained under-treated because of inadequate assessment. Measuring lactate concentration has been recommended to help physicians detect [26] and manage severe infections [27]. We observed that lactate was infrequently measured in the present series. Therefore, procedures to optimise detection of severe infection were partially applied in our patients that did not seem to be perceived as severely ill.
A burden of evidence supports the paramount role of early recognition and prompt management of severe infection, and admission to the ICU when applicable [27]. The prognosis of patients with severe infection actually depends on their initial management; that is, treatment received in the ED for half of patients [28]. We observed that few patients received adequate antimicrobial therapy or fluid challenge in an appropriate time-span. We therefore conclude that patients with severe infection were under-treated. Similar findings were reported in a large Spanish study [29], as an incredibly low rate of patients admitted with SS/SSh received process-of-care according to bundles, even after an educational program involving physicians and nurses of the ED and ICU. An inadequate initial assessment may result from difficulties to correctly implement guidelines in a busy ED. First, equipment and physicians' skills to provide complex technical procedures to patients vary betwen hospitals [30]. Barriers can also be related to time consumption of procedures necessary to implement procedures for severe infections. In addition, all team leaders are not fully confident in guidelines to treat severe infections [31]. However, we checked fluid loading and delay to first antimicrobial agent that do not require specific skills or organisation. We observed that these basic treatments were not correctly delivered. In a series of sepsis with hypotension, the delay to antimicrobial agents was over six hours in more than half of patients because infection was not recognised. We believe that most patients were not treated according to guidelines because initial assessment failed to detect the severity of disease.

Despite the efforts in the past decade to produce and distribute specific guidelines for treating severe infection, difficulties persist to detect SS/SSh even in typically at-risk patients such as those with febrile neutropenia. 
Table 7 Factors associated with adequate management

\begin{tabular}{|c|c|c|c|c|}
\hline Variables & & $\begin{array}{l}\text { Adequate management } \\
\qquad(\mathrm{n}=33)\end{array}$ & $\begin{array}{l}\text { Inadequate management } \\
\qquad(\mathrm{n}=161)\end{array}$ & $P$ \\
\hline \multirow[t]{2}{*}{ Tertiary teaching hospital } & Yes & $24(12)$ & $92(88)$ & 0.1 \\
\hline & No & $9(21)$ & $68(79)$ & \\
\hline \multirow[t]{2}{*}{ Number of ED visits during study period } & $<20000$ & $17(18)$ & $78(82)$ & 0.80 \\
\hline & $\geq 20000$ & $15(16)$ & $76(84)$ & \\
\hline \multirow[t]{2}{*}{ Unit for cancer patients } & Yes & $29(18)$ & $132(82)$ & 1 \\
\hline & No & $4(15)$ & $22(85)$ & \\
\hline \multirow[t]{2}{*}{ Written procedures for febrile neutropenia management } & Yes & $24(21)$ & $92(79)$ & 0.16 \\
\hline & No & $9(13)$ & $62(87)$ & \\
\hline Age (mean $\pm S D)$ & & $58 \pm 17$ & $61 \pm 14$ & 0.30 \\
\hline \multirow[t]{2}{*}{ Sex } & Male & $17(15)$ & $97(85)$ & 0.29 \\
\hline & Female & $16(21)$ & $61(79)$ & \\
\hline Karnosfsky index (median (range)) & & $70(30-100)$ & $80(30-100)$ & 0.07 \\
\hline \multirow[t]{2}{*}{ Place of stay } & Home & $30(18)$ & $139(82)$ & 0.23 \\
\hline & House care & $2(40)$ & $3(60)$ & \\
\hline \multirow[t]{2}{*}{ Underlying disorder } & Yes & $12(17)$ & $60(83)$ & 0.78 \\
\hline & No & $21(18)$ & $94(82)$ & \\
\hline \multirow[t]{2}{*}{ Type of cancer } & Haematological & $14(17)$ & $70(83)$ & 0.91 \\
\hline & Solid cancer & $19(17)$ & $91(83)$ & \\
\hline \multirow[t]{2}{*}{ Presence of metastasis or uncontrolled } & Yes & $22(17)$ & $108(83)$ & 0.96 \\
\hline & No & $11(17)$ & $53(83)$ & \\
\hline \multirow[t]{2}{*}{ Antimicrobial therapy prior to ED } & Yes & $9(9)$ & $39(91)$ & 0.75 \\
\hline & No & $24(17)$ & $119(83)$ & \\
\hline \multirow[t]{2}{*}{ Time of ED visit } & Day & $18(15)$ & $102(85)$ & 0.24 \\
\hline & Night & $15(22)$ & $54(78)$ & \\
\hline \multirow[t]{2}{*}{ Level of nurse triage } & $<3$ & $20(22)$ & $73(78)$ & 0.43 \\
\hline & $\geq 3$ & $8(16)$ & $42(84)$ & \\
\hline \multirow[t]{2}{*}{ Presence of severity signs according to ED physician } & Yes & $9(17)$ & $45(83)$ & 0.82 \\
\hline & No & $24(18)$ & $109(82)$ & \\
\hline \multirow[t]{2}{*}{ Severe sepsis } & Yes & $6(7)$ & $80(93)$ & 0.0009 \\
\hline & No & $27(25)$ & $81(75)$ & \\
\hline \multirow[t]{2}{*}{ Cancer specialist advice } & Yes & $14(17)$ & $70(83)$ & 0.95 \\
\hline & No & $18(17)$ & $88(83)$ & \\
\hline \multirow[t]{2}{*}{ MASCC classification } & High risk & $32(31)$ & $71(69)$ & $<0.001$ \\
\hline & Low risk & $1(1)$ & $90(99)$ & \\
\hline \multirow[t]{2}{*}{ Protective isolation } & Yes & $29(19)$ & $128(81)$ & 0.50 \\
\hline & No & $4(13)$ & $26(87)$ & \\
\hline \multirow[t]{2}{*}{ Surgical management } & Yes & $2(50)$ & $2(50)$ & 0.12 \\
\hline & No & $26(15)$ & $146(85)$ & \\
\hline \multirow[t]{2}{*}{ Adequate orientation } & Agree & $26(17)$ & $129(83)$ & 0.65 \\
\hline & Disagree & $7(20)$ & $28(80)$ & \\
\hline
\end{tabular}

Values shown are number and percentage unless stated otherwise. $P$ values below 0.05 are statistically significant.

ED, emergency department; G-CSF, granulocyte-cell stimulating factor; MASCC, Multinational Association for Supportive Care in Cancer; SD, standard deviation.

Delay to first antimicrobial agent has an impact on prognosis in patients presenting infection with severity criteria [32]. Guidelines to treat patients with SS/SSh endorse that first dose of antibiotics should be given in a timespan shorter than 90 minutes [9]. Whereas it can be assumed that earlier antimicrobial agents would improve prognosis in febrile neutropenia, no evidence can currently lead to any recommendations about delay.
Consequently, guidelines to treating patients with febrile neutropenia are not clear regarding delays to treatment; therefore, objectives are easier to obtain. This may partly explain why management of patients without SS/SSh frequently reached goals.

A puzzling result is that supportive care was not modified by the intervention of the oncologist or haematologist: the presence of a medical unit dedicated to 
cancer in the same hospital, the existence of written procedures about febrile neutropenia, or the oncologist's advice did not improve the quality of care. Despite recent validation studies, the relevance of MASCC to guide site of care can be limited because several cornerstone items are missing from this evaluation tool [18]. This supports the fact that the assessment of severity of infection in a short time-span appears to be particularly challenging in onco-haematological patients [33].

The study has several limitations. Whereas simplicity of the study design presumably improved acceptability and feasibility, we cannot rule out that patients could be missed because making clinical research around the clock is sometimes difficult in busy EDs. Our study did not follow up the patients. It was decided to carry out a descriptive study and patients' outcomes were not recorded. Thus, it is unknown whether the prognosis of the patients with febrile neutropenia would have changed if recommendations had been implemented. In addition, the study was proposed to 350 French hospitals, but only 47 took part. Therefore, results could have been biased because EDs that participated were possibly more involved in the management of patients with sepsis and/ or cancer. However, these centres were geographically distributed across France and were representative of French EDs because they were mostly set in general hospitals. In addition, only 19 Eds had a written procedure for febrile neutropenia. The convenience series was also limited because no patient waived the invitation to participate in this prospective study. Another limitation was the use of MASCC criteria to decide on the site of care and antimicrobial therapy because this score has never been validated in the ED setting. Stratification of patients using the MASCC scoring system is debatable as consensus meetings suggest that it is not superior to expert advice. However, the MASCC classification has been regularly used as a gold standard to stratify patients with febrile neutropenia. In addition MASCC calculation depends on the burden of the onco-haematological disorder. However, it is usually accepted that patients with advanced cancer under-estimate the severity of the disorder [34,35]. As emergency physicians usually obtain past medical history from patients' interviews, they may misclassify severity of febrile neutropenia when assessed by MASCC level. Finally, we found that patients with more severe and mild febrile neutropenia were inadequately treated according to a univariate analysis. We were unable to identify risk factors for inadequate management by a multivariate analysis, partly because of the size of the sample.

\section{Conclusions}

Patients with febrile neutropenia who visit the EDs are likely to develop severe infection. In this sample, patients who met our definition of SS/SSh had a low rate of being treated with adequate fluid and a low rate of evaluation with serum lactate level. Patients who were considered to be low risk were often admitted to the hospital rather than being discharged home on oral antibiotics. More work is needed within the standard operation protocols of EDs as well as outcome-based research to optimise care for these patients.

\section{Key messages}

- Patients with febrile neutropenia are likely to present to the ED with severe infections.

- More severe patients are poorly recognised and under-treated.

- Patients with mild disorders are over-treated.

- Patients with febrile neutropenia presenting to the ED are usually not treated according to guidelines.

\section{Abbreviations}

ED: emergency department; G-CSF: granulocyte-cell stimulating factor; MASCC: Multinational Association of Supportive Care in Cancer; SS: severe sepsis; SSh: septic shock.

\section{Acknowledgements}

This study was supported by Amgen France. The funding source did not participate in the study design, data collection, analysis, interpretation of data, writing of the manuscript or the decision to submit the manuscript for publication.

We are indebted to Dr Eric Leuteneger and ABR Pharma for their valuable technical and logistical support. The study was approved by the French Society of Emergency Medicine (Société Française de Médecine d'Urgence, SFMU)

We are very grateful to all local investigators who participated in the recruitment of patients: (01) Ain: CH Bourg-en-Bresse, Dr Eskandinian; (03) Allier: CH Vichy, Dr Limoges; (06) Alpes Maritimes: CHU Nice, Dr Burgos; (07) Ardèche: CH Annonay, Dr Gauclere; (07) Ardèche: CH Aubenas, Dr Barjon; (09) Ariège: CH Val d'Ariège, Dr Mimoun; (13) Bouches-du-Rhône: CH Martigues, Dr Durand; (15) Cantal: CH Aurillac, Dr Dejou; (15) Cantal: CH Mauriac, Dr Lamalle; (17) Charente-Maritime: CH La Rochelle, Dr Tabary; (17) Charente-Maritime: CH Rochefort sur Mer, Dr Fazilleau; (19) Corrèze: CH Tulles, Dr Beaujean; (22) Côtes d'Armor: CH Saint Brieuc, Dr Floch; (24) Dordogne: CH Périgueux, Dr Ely; (26) Drôme: CH Valence, Dr Abou Abbas; (28) Eure et Loire: $\mathrm{CH}$ Chartres, Dr Maisonnier; (35) lle et Vilaine: $\mathrm{CH}$ Saint Malo, Dr Verley; (36) Indre: CH Le Blanc, Dr Sylvestre; (37) Indre et Loire: CH Chinon, Dr Gerard; (37) Indre et Loire: CHU Tours, Pr Lanotte; (38) Isère: CHU Grenoble, Dr Ara Somohano; (40) Landes: CH Mont de Marsan, Dr Harambat; (42) Loire: CHU Saint Etienne, Dr Viallon; (44) Loire Atlantique: CH Châteaubriant, Dr Hourdin; (45) Loiret: CH Montargis, Dr Klein; (45) Loiret: CH Orléans, Dr Martin; (47) Lot et Garonne: CH Agen, Dr De Bortoli; (49) Maine et Loire: CHU Angers, Dr Pattier; (54) Meurthe et Moselle: $\mathrm{CH}$ Lunéville, Dr Rosa; (59) Nord: CH Dunkerque, Dr Delangue; (62) Pas de Calais: CH Saint Omer, Dr Capelle; (63) Puy de Dôme: CH Thiers, Dr Poitrineau; (63) Puy de Dôme: CHU Clermont Ferrand, Dr Peyrat; (64) Pyrénées Atlantiques: CH Bayonne, Dr Sevilla; (64) Pyrénées Atlantiques: CH Pau, Dr Mangon; (71) Saône et Loire: CH Mâcon, Dr Delbrassine; (72) Sarthe: CH Le Mans, Dr Coroller-Bec; (75) Paris: CHU Cochin, Dr André; (75) Paris: CHU Hôtel Dieu, Dr Kierzek; (75) Paris: CHU Pitié-Salpétrière, Dr Delerme; (75) Paris: CHU Saint Antoine, Dr Chaille; (75) Paris: CHU Saint Louis, Dr Taboulet; (75) Paris: CHU Tenon, Dr Cassy; (79) Deux Sèvres: CH Niort, Dr Delaunoy; (81) Tarn: CH Albi, Dr Depierre; (91) Essonne: CH Longjumeau, Dr Andrianjafy; (94) Créteil: CHU Henri Mondor, Dr Santin.

\section{Author details}

'Department of Emergency Medicine, Hôpital Cochin, APHP, 27, rue du Faubourg Saint-Jacques, F-75679 Paris Cedex 14, France. ' $U$ niversité Paris 
Descartes, 12, rue de l'Ecole de Médecine, 75006 Paris, France. ${ }^{3}$ Department of Emergency Medicine, Hôpital Saint-Louis, APHP, 1 avenue ClaudeVellefaux, 75010 Paris, France. ${ }^{4}$ Department of Biostatistics, Hôpital Necker APHP, 149 rue de Sèvres, 75015 Paris, France. ${ }^{5}$ Department of Haematology, Hôpital Haut-Lévêque, Groupe Hospitalier Sud, CHU de Bordeaux, Avenue de Magellan, 33604 Pessac Cedex, France. 'Department of Emergency Medicine, Hôpital Necker, APHP, 149 rue de Sèvres, 75015 Paris, France. ${ }^{7}$ Department of Emergency Medicine, Hôtel-Dieu, APHP, 1 place du Parvis Notre-Dame, 75004 Paris, France. ${ }^{8}$ Department of Emergency Medicine, Hôpital Purpan, CHU de Toulouse, Place du Docteur Baylac, 31059 Toulouse Cedex 9, France.

\section{Authors' contributions}

SA contributed to the conception, design, and drafting of the manuscript. PT contributed to collection of the data. CE contributed to interpretation and analysis of data and drafting the manuscript. NM contributed to the critical revision of the manuscript. MN contributed to the management of the study. GK contributed to collection of the data. MB contributed to collection of the data. FP contributed to collection of the data. SC contributed to collection of the data. HC contributed to collection of the data. JLP contributed to the critical revision of the manuscript. YEC contributed to the conception, design, interpretation and analysis of data and drafting the manuscript.

\section{Competing interests}

Yann-Erick Claessens received fees from Amgen France. All other authors declare that they have no competing interests.

Received: 6 November 2009 Revised: 12 January 2010

Accepted: 19 April 2010 Published: 19 April 2010

\section{References}

1. Armstrong D, Young LS, Meyer RD, Blevins AH: Infectious complications of neoplastic disease. Med Clin North Am 1971, 55:729-745.

2. Barber FD: Management of fever in neutropenic patients with cancer. Nurs Clin North Am 2001, 36:631-644.

3. Charlson ME, Pompei P, Ales KL, Mackenzie CR: A new method of classifying prognostic comorbidity in longitudinal studies: development and validation. J Chronic Dis 1987, 40:373-383.

4. Rolston KV, Tarrand JJ: Pseudomonas aeruginosa - still a frequent pathogen in patients with cancer: 11-year experience at a comprehensive cancer center. Clin Infect Dis 1999, 29:463-464.

5. Talcott JA, Rubenstein EB: Initial clinical evaluation and risk assessment of the febrile neutropenic patient. Textbook of Febrile Neutropenia London: Martin DunitzKenneth VI Rolston, Edward B Rubenstein 2001, 151-165.

6. Klastersky J, Paesmans M, Rubenstein EB, Boyer M, Elting L, Feld R, Gallagher J, Herrstedt J, Rapoport B, Rolston K, Talcott J: The Multinational Association for Supportive Care in Cancer risk index: A multinational scoring system for identifying low-risk febrile neutropenic cancer patients. J Clin Oncol 2000, 18:3038-3051.

7. Levy MM, Fink MP, Marshall JC, Abraham E, Angus D, Cook D, Cohen J, Opal SM, Vincent JL, Ramsay G, International Sepsis Definitions Conference: $2001 \mathrm{SCCM} / \mathrm{ESICM} / \mathrm{ACP} / \mathrm{ATS} / \mathrm{SIS}$ International Sepsis Definitions Conference. Intensive Care Med 2003, 29:530-538.

8. Prise en charge hémodynamique du sepsis sévère (nouveau-né exclu). [http://www.sfmu.org/documents/consensus/cc_sepsis.pdf]

9. Dellinger RP, Carlet JM, Masur H, Gerlach H, Calandra T, Cohen J, GeaBanacloche J, Keh D, Marshall JC, Parker MM, Ramsay G, Zimmerman JL, Vincent JL, Levy MM, Surviving Sepsis Campaign Management Guidelines Committee: Surviving Sepsis Campaign guidelines for management of severe sepsis and septic shock. Crit Care Med 2004, 32:858-873.

10. Conférence de consensus 2007: Prise en charge initiale des états septiques graves de l'adulte et de l'enfant.[http://www.sfmu.org/ documents/consensus/Groupe\%20Transversal\%20Sepsis\%20Fn.doc].

11. Dhainaut JF, Claessens $Y E$, Janes J, Nelson DR: Underlying disorders and their impact on the host response to infection. Clin Infect Dis 2005, 41: S481-489.

12. Shapiro NI, Wolfe RE, Moore RB, Smith E, Burdick E, Bates DW: Mortality in Emergency Department Sepsis (MEDS) score: a prospectively derived and validated clinical prediction rule. Crit Care Med 2003, 31:670-675.
13. Cordonnier C, Magnier C, Leverger G, Ghanassia JP, Herbrecht R, pour le groupe Clioh: Résultats d'une enquête de pratique en onco-hématologie réalisée en France en 2001. Press Med 2004, 33:324-326.

14. Rezende E, Silva JM Jr, Isola AM, Campos EV, Amendola CP, Almeida SL: Epidemiology of severe sepsis in the emergency department and difficulties in the initial assistance. Clinics (Sao Paulo) 2008, 63:457-464.

15. Strehlow MC, Emond SD, Shapiro NI, Pelletier AJ, Camargo CA: National study of emergency department visits for sepsis, 1992 to 2001. Ann Emerg Med 2006, 48:326-331.

16. Evolution de l'incidence et de la mortalité par cancer en France de 1978 à 2000). [http://www.invs.sante.fr/publications/2003/rapport_cancer_2003/ index.html].

17. Bone RC: Sepsis, the sepsis syndrome, multiorgan failure: a plea for comparable definitions. Ann Intern Med 1991, 114:332-333.

18. Hughes WT, Armstrong D, Bodey GP, Bow EJ, Brown AE, Calandra T, Feld R, Pizzo PA, Rolston KV, Shenep JL, Young LS: 2002 guidelines for the use of antimicrobial agents in neutropenic patients with cancer. Clin Infect Dis 2002, 34:730-751.

19. Kern WV: Risk assessment and risk-based therapeutic strategies in febrile neutropenia. Curr Opin Infect Dis 2001, 14:415-422.

20. Rolston KV: New trends in patient management: risk-based therapy for febrile patients with neutropenia. Clin Infect Dis 1999, 29:515-521.

21. Wang HE, Shapiro NI, Angus DC, Yealy DM: National estimates of severe sepsis in United States emergency departments. Crit Care Med 2007, 35:1928-1936.

22. Angus DC, Linde-Zwirble WT, Lidicker J, Clermont G, Carcillo J, Pinsky MR: Epidemiology of severe sepsis in the United States: analysis of incidence, outcome, and associated costs of care. Crit Care Med 2001, 29:1303-1310.

23. Petrelli NJ, Winer EP, Brahmer J, Dubey S, Smith S, Thomas C, Vahdat LT, Obel J, Vogelzang N, Markman M, Sweetenham JW, Pfister D, Kris MG, Schuchter LM, Sawaya R, Raghavan D, Ganz PA, Kramer B: Clinical Cancer Advances 2009: major research advances in cancer treatment, prevention, and screening-a report from the American Society of Clinical Oncology. J Clin Oncol 2009, 27:6052-6069.

24. Aapro MS, Cameron DA, Pettengell R, Bohlius J, Crawford J, Ellis M, Kearney N, Lyman GH, Tjan-Heijnen VC, Walewski J, Weber DC, Zielinski C, European Organisation for Research and Treatment of Cancer (EORTC) Granulocyte Colony-Stimulating Factor (G-CSF) Guidelines Working Party: EORTC guidelines for the use of granulocyte-colony stimulating factor to reduce the incidence of chemotherapy-induced febrile neutropenia in adult patients with lymphomas and solid tumours. Eur I Cancer 2006, 42:2433-2453.

25. Hayes NA: Analyzing current practice patterns: lessons from Amgen's Project Chemolnsight. Oncol Nurs Forum 2001, 28:11-16.

26. Rady MY, Rivers EP, Martin GB, Smithline H, Appelton T, Nowak RM: Continuous central venous oximetry and shock index in the emergency department: use in the evaluation of clinical shock. Am J Emerg Med 1992, 10:538-541.

27. Arnold RC, Shapiro NI, Jones AE, Schorr C, Pope J, Casner E, Parrillo JE, Dellinger RP, Trzeciak $S$, on behalf of the Emergency Medicine Shock Research Network (EMShockNet) Investigators: Multi-center study of early lactate clearance as a determinant of survival in patients with presumed sepsis. Shock 2009, 32:35-39.

28. Alberti C, Brun-Buisson C, Burchardi H, Martin C, Goodman S, Artigas A, Sicignano A, Palazzo M, Moreno R, Boulmé R, Lepage E, Le Gall R: Epidemiology of sepsis and infection in ICU patients from an international multicentre cohort study. Intensive Care Med 2002, 28:108-121.

29. Ferrer R, Artigas A, Levy MM, Blanco J, González-Díaz G, GarnachoMontero J, Ibáñez J, Palencia E, Quintana M, de la Torre-Prados MV Edusepsis Study Group: Improvement in process of care and outcome after a multicenter severe sepsis educational program in Spain. JAMA 2008, 299:2294-2303.

30. Yu DT, Black E, Sands KE, Schwartz JS, Hibberd PL, Graman PS, Lanken PN, Kahn KL, Snydman DR, Parsonnet J, Moore R, Platt R, Bates DW, Academic Medical Center Consortium Sepsis Project Working Group: Severe sepsis: variation in resource and therapeutic modality use among academic centers. Crit Care 2003, 7:R24-R34. 
31. Carlbom DJ, Rubenfeld GD: Barriers to implementing protocol-based sepsis resuscitation in the emergency department-results of a national survey. Crit Care Med 2007, 35:2525-2532.

32. Kumar A, Roberts D, Wood KE, Light $B$, Parrillo JE, Sharma S, Suppes $R$, Feinstein D, Zanotti S, Taiberg L, Gurka D, Kumar A, Cheang M: Duration of hypotension before initiation of effective antimicrobial therapy is the critical determinant of survival in human septic shock. Crit Care Med 2006, 34:1589-1596.

33. Velasco E, Portugal RD, Salluh Jl: A simple score to predict early death in adult cancer patients with bloodstream infections. J Infect 2009, 59:332-336.

34. Chow E, Andersson L, Wong R, Vachon M, Hruby G, Franssen E, Fung KW, Harth T, Pach B, Pope J, Connolly R, Schueller T, Stefaniuk K, Szumacher E, Hayter C, Finkelstein J, Danjoux C: Patients with advanced cancer: a survey of the understanding of their illness and expectations from palliative radiotherapy for symptomatic metastases. Clin Oncol ( $R$ Coll Radiol) 2001, 13:204-208.

35. Tchen N, Bedard P, Yi QL, Klein M, Cella D, Eremenco S, Tannock IF: Quality of life and understanding of disease status among cancer patients of different ethnic origin. Brit J Cancer 2003, 89:641-647.

doi:10.1186/cc8972

Cite this article as: André et al.: Febrile neutropenia in French emergency departments: results of a prospective multicentre survey. Critical Care 2010 14:R68

\section{Submit your next manuscript to BioMed Central and take full advantage of:}

- Convenient online submission

- Thorough peer review

- No space constraints or color figure charges

- Immediate publication on acceptance

- Inclusion in PubMed, CAS, Scopus and Google Scholar

- Research which is freely available for redistribution

Submit your manuscript at www.biomedcentral.com/submit 